Revue

Revue de l'histoire des religions

de Ihistoire des religions

\title{
Anne BAUD et Christian SAPIN (dir.), Cluny : les
} origines du monastère et de ses églises

Paris, CTHS («Collection archéologie et histoire de l'art », 35), 2019

Alain Rauwel

\section{CpenEdition}

\section{Journals}

Édition électronique

URL : https://journals.openedition.org/rhr/10667

DOI : $10.4000 /$ rhr. 10667

ISSN : 2105-2573

Éditeur

Armand Colin

Édition imprimée

Date de publication : 1 septembre 2020

Pagination : 463-465

ISBN : $978-2-200-93327-2$

ISSN : 0035-1423

Référence électronique

Alain Rauwel, "Anne Baud et Christian SAPIN (dir.), Cluny : les origines du monastère et de ses églises », Revue de l'histoire des religions [En ligne], 3 | 2020, mis en ligne le 01 janvier 2021, consulté le 06 janvier 2023. URL : http://journals.openedition.org/rhr/10667 ; DOl : https://doi.org/10.4000/rhr.10667

Ce document a été généré automatiquement le 6 janvier 2023

Tous droits réservés 


\title{
Anne BAUD et Christian SAPIN (dir.), Cluny : les origines du monastère et de ses églises
}

Paris, CTHS («Collection archéologie et histoire de l'art », 35), 2019

\author{
Alain Rauwel
}

\section{RÉFÉRENCE}

Anne BAUD et Christian SAPIN (dir.), Cluny : les origines du monastère et de ses églises, Paris, CTHS (« Collection archéologie et histoire de l'art », 35), 2019, 223 p., $26 \mathrm{~cm}, 55 €$, 978-2-7355-0906-5.

1 Le bel album préparé par les directeurs du chantier archéologique pluriannuel de cluny est publié d'abord et avant tout pour donner à la communauté des archéologues le résultat des campagnes de recherches menées entre 2006 et 2013. Comme tel, il décrit soigneusement les vestiges découverts, en avance des interprétations formelles et justifie systématiquement toutes les propositions par une documentation technique luxueuse sans être luxuriante : clichés, croquis, annexes diverses recensant le mobilier, les matériaux, les monnaies... Est-ce à dire que l'ouvrage est exclusivement technique et que sa consultation est réservée aux professionnels de l'excavation? Nullement. L'historien du monachisme ne saurait s'en passer, tant le site fouillé est d'une importance capitale, tant aussi les résultats obtenus s'imposent désormais dans toute évaluation correcte du phénomène clunisien, trop souvent exalté sur des bases plus touristico-mémorielles que scientifiques. L'ecclesia cluniacensis, on le sait bien, a étendu ses branches (d'aucuns diront ses tentacules) sur toute l'Europe féodale. Le simple fait qu'elle se soit donnée à elle-même ce nom privilégié d'ecclesia rend encore plus décisive la connaissance des formes prises par les lieux cultuels de l'abbaye placée à la tête du réseau. Or, comme le titre du volume le souligne, ce sont précisément ces lieux 
consacrés qui sont au cœur des travaux menés par Anne Baud, Christian Sapin et leurs équipes.

2 Un examen à nouveaux frais s'imposait d'autant plus que le poids de l'historiographie est ici très lourd. On a beaucoup écrit, ces dernières décennies, sur Cluny et ses bâtiments. Et toute cette littérature a été produite sur la base des restitutions proposées par un archéologue américain de grand talent, Kenneth John Conant, dont les recherches de terrain ont commencé à Cluny dès 1928, mais qui n'a publié son opus magnum qu'en 1968. Les investigations de Conant sont remarquablement documentées, grâce à un vaste ensemble de notes, relevés et croquis conservé à Cluny même. Dans un beau chapitre, le regretté Walter Berry propose une «réévaluation » des travaux de Conant, entrant dans le détail de ses méthodes et indiquant ce que l'on peut et ce que l'on ne peut pas attendre des fameux plans d'ensemble synthétisant sa conception du site et mille fois reproduits (ce sera désormais une faute !). Le vétéran de l'archéologie clunisienne a en effet suggéré des restitutions très précises à partir d'une base matérielle très limitée, qu'il fallait absolument reprendre et étendre.

C'est ce qu'ont fait A. Baud et C. Sapin. Leurs sondages n'ont pas tant porté sur l'illustre abbatiale dite "Cluny III ", déjà bien connue (notamment grâce à A. Baud elle-même), que sur les bâtiments cultuels antérieurs, en lien avec un lieu très ritualisé aussi et situé au voisinage immédiat des églises, le chapitre. L'histoire de Cluny commence avant les moines, par une villa, déjà pourvue d'une chapelle, qui passe au comte Guérin sous Louis le Pieux et que l'abbesse Ava cède à son frère Guillaume, duc d'Aquitaine, en 893. Cette villa fait précisément l'objet de la célèbre donation de 910 à Bernon et à ses religieux. Ces derniers n'eurent qu'à s'installer dans des espaces déjà organisés et bâtis, sur lesquels les fouilles récentes donnent des précisions absolument inédites. L'un des éléments spectaculaires du chantier a été la (re)découverte d'un sarcophage du vi ${ }^{\mathrm{e}}$ $\mathrm{VII}^{\mathrm{e}}$ siècle remployé pour la sépulture d'une femme nommée Ava et qui a de bonnes chances d'être la sœur du fondateur, peut-être instigatrice de la vie régulière en val de Grosne avec quelques pieuses femmes. À proximité immédiate, l'oratoire prémonastique était une petite pièce de $10 \times 5 \mathrm{~m}$. Bien vite il s'est révélé insuffisant pour la vie liturgique d'un groupe en pleine expansion et a débuté la construction de ce que l'on nomme ordinairement "Cluny II ", dont le chevet et le transept ont pu être méthodiquement explorés (avec la crypte qui a enrichi l'ensemble dans un premier temps). C. Sapin montre parfaitement comment Cluny II est une église qui évolue tout au long du $\mathrm{x}^{\mathrm{e}}$ siècle, avec des reprises régulières des parties orientales et la création d'absidioles. Les historiens de la liturgie se réjouiront d'apprendre ici que les fouilles ont été l'occasion de mettre au jour la base de l'autel majeur du premier Cluny, dont le bon état a permis de déduire la forme générale, intégrant probablement un reliquaire, ainsi que les traces d'un ciborium dominant la table eucharistique. La restitution de l'ensemble, présentée en pleine page, est en son genre un événement.

À peu de distance, la documentation écrite et les fouilles de Conant donnent à connaître une autre chapelle, Sainte-Marie, tôt liée à l'infirmerie, qui a pu elle aussi bénéficier d'une véritable couverture archéologique. L'exposé des données était très attendu car la présence, à l'arrière du carré claustral, d'une ecclesia infirmorum a tendance à être considérée comme une "signature " de l'appartenance à l'orbite clunisienne. Cette spécificité s'explique avant tout par des coutumes liturgiques, et c'est une grande force de ce magnifique rapport de fouilles que d'intégrer pleinement les données rituelles, 
même si la question des rapports entre le normatif et le « descriptif » doit toujours être posée quand on aborde l'abondante série des coutumiers clunisiens. L'importance de Sainte-Marie est vérifiée par sa reconstruction sous l'abbatiat d'Hugues de Semur, à proximité de la salle du chapitre du nouveau cloître, elle aussi systématiquement fouillée et dont on connaît maintenant le profil à double rangée de banquettes. Ce sont ainsi des pages capitales qui viennent d'être écrites dans le «livre ouvert» qu'est Cluny, comme le disent très justement les auteurs du volume. Mais ce livre est loin d'être clos, et s'il plait à la Providence, et surtout aux administrateurs du patrimoine, les prochaines générations d'archéologues ne devraient pas chômer en val de Grosne.

\section{AUTEURS}

\section{ALAIN RAUWEL}

Université de Bourgogne. 